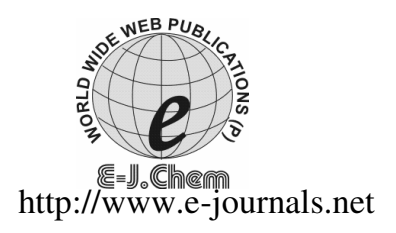

ISSN: 0973-4945; CODEN ECJHAO

E-Journal of Chemistry

2011, 8(1), 264-268

\title{
Kinetics and Oxidation of Substituted Benzyl Alcohols by Phenyliodoso Acetate
}

\author{
R.GIRIJA* and S.ARUNA \\ Department of Chemistry \\ Queen Mary's College, Chennai-600004, India \\ nnrsharan@gmail.com
}

Received 5 May 2010; Accepted 18 July 2010

\begin{abstract}
Oxidation of benzyl alcohol and some meta- and para- substituted alcohols by phenyliodoso acetate (PIA) in $t$-butyl alcohol-water medium (50:50) leads to the formation of corresponding benzaldehyde. The stoichiometry of the reaction was found to be 1:1. The reaction was first order each in substrate and oxidant concentrations. This reaction was studied at four different temperatures and the activation parameters were calculated. Correlation analysis was carried out using Taft's and Swain's dual substituent parameter (DSP) equation. The rate data of meta- compounds showed good correlation with $(\mathrm{F}, \mathrm{R})$ values, para-substituted benzyl alcohols showed good correlation with $\sigma_{\mathrm{I}} \sigma_{\mathrm{R}}{ }^{+}$A suitable mechanism has been proposed.
\end{abstract}

Keywords: Phenyliodoso acetate, Kinetics, Benzyl alcohols, Oxidation.

\section{Introduction}

Pausaucker $e t a l^{1}$ have studied that the oxidation of primary and secondary alcohols by phenyliodoso acetate (PIA) is not facile. Vaidyanathan and Venkatasubramaniam ${ }^{2}$ reported the oxidation of $\alpha$-hydroxy acids by phenyliodoso acetate in acetic acid medium and they found in aqueous medium only free radical and ionic mechanism is possible. The oxidation of various organic compounds by phenyliodoso acetate was studied ${ }^{3-9}$.

Phenyliodoso acetate was found to be a good oxidizing agent in the synthesis of isoflavan quinones ${ }^{11}$. Redox properties of marine natural products were studied by PIA ${ }^{12}$. This communication deals with the kinetics and mechanism of oxidation of meta- and parasubstituted benzyl alcohols by PIA in $t$-butyl alcohol-water medium. PIA acts as a good oxidizing agent.

\section{Experimental}

Benzyl alcohol and substituted benzyl alcohols were purified by repeated distillation and recrystallization. Phenyliodoso acetate was prepared by the reported method ${ }^{10}$. 
All the kinetic measurements were carried out in a glass stoppered iodine flask protected from light and thermostated. Reactions were carried out in $t$-butyl alcohol-water medium at $30 \pm 1{ }^{\circ} \mathrm{C}$ in the presence of $2.5 \times 10^{-3} \mathrm{M}$ sulphuric acid unless otherwise stated. The course of the reaction was followed iodometrically.

\section{Stoichiometry and product analysis}

Stoichiometry of the reaction was found to be 1:1. The product analysis was carried out by mixing equimolar mixture of benzyl alcohol and phenyliodoso acetate and kept at room temp for $24 \mathrm{~h}$ under the kinetic conditions employed. Then the mixture was poured into a china dish and concentrated to a small volume by spontaneous evaporation. It was extracted with ether and the ether extract was dried over anhydrous sodium sulphate. Then the ether evaporated to get the liquid product. From IR and UV spectra, the extracted mixture was analyzed and it showed that the sole product was benzaldehyde.

\section{Results and Discussion}

The oxidation of benzyl alcohol by phenyliodoso acetate has been carried out in 50:50 tert-butylalcohol-water medium in presence of $2.5 \times 10^{-3} \mathrm{M}$ sulphuric acid. The rate data observed is given in Table 1.

The reaction is found to be first order with respect to [PIA]. A plot of $\log \mathrm{k}_{\mathrm{obs}} v s$. $\log [\mathrm{BzOH}]$ gave a straight line with unit slope indicating first order with respect of $[\mathrm{BzOH}]$. In order to know the role of $\mathrm{H}_{2} \mathrm{SO}_{4}$ the reaction was carried out in the absence of $\mathrm{H}_{2} \mathrm{SO}_{4}$ It has been observed that the rate of the reaction increases with increase in $\mathrm{H}_{2} \mathrm{SO}_{4}$.

Table 1. Effect of varying $[\mathrm{BzOH}],[\mathrm{PIA}],\left[\mathrm{H}^{+}\right]$and the solvent composition on the reaction rate temperature $303 \mathrm{~K}$.

\begin{tabular}{ccccc}
\hline $\begin{array}{c}\text { PIA }] \times 10^{4} \\
\mathrm{~mol} \mathrm{dm}^{-3}\end{array}$ & $\begin{array}{c}{[\mathrm{BzOH}] \times 10^{3}} \\
\mathrm{~mol} \mathrm{dm}^{-3}\end{array}$ & $\begin{array}{c}{\left[\mathrm{H}^{+}\right] \times 10^{3}} \\
\mathrm{~mol} \mathrm{dm}^{-3}\end{array}$ & $\begin{array}{c}\% \text { of } t-\mathrm{BuOH}- \\
\mathrm{H}_{2} \mathrm{O}\end{array}$ & $\begin{array}{c}k_{\mathrm{obs}} \times 10^{3} \\
\mathrm{~s}^{-1}\end{array}$ \\
\hline 1.0 & 1.0 & 2.5 & $50-50$ & 3.78 \\
1.0 & 2.0 & 2.5 & $50-50$ & 7.51 \\
1.0 & 3.0 & 2.5 & $50-50$ & 11.40 \\
1.0 & 4.0 & 2.5 & $50-50$ & 15.10 \\
1.0 & 5.0 & 2.5 & $50-50$ & 19.00 \\
0.5 & 2.0 & 2.5 & $50-50$ & 7.21 \\
1.0 & 2.0 & 2.5 & $50-50$ & 7.51 \\
1.5 & 2.0 & 2.5 & $50-50$ & 7.62 \\
2.0 & 2.0 & 2.5 & $50-50$ & 7.80 \\
2.5 & 2.0 & 2.5 & $50-50$ & 7.82 \\
1.0 & 2.0 & 1.5 & $50-50$ & 4.50 \\
1.0 & 2.0 & 2.0 & $50-50$ & 6.10 \\
1.0 & 2.0 & 2.5 & $50-50$ & 7.51 \\
1.0 & 2.0 & 3.0 & $50-50$ & 9.00 \\
1.0 & 2.0 & 3.5 & $50-50$ & 10.50 \\
1.0 & 2.0 & 2.5 & $30-70$ & 3.88 \\
1.0 & 2.0 & 2.5 & $40-60$ & 5.49 \\
1.0 & 2.0 & 2.5 & $50-50$ & 7.51 \\
1.0 & 2.0 & 2.5 & $60-40$ & 9.32 \\
1.0 & 2.0 & 2.5 & $70-30$ & 11.10 \\
\hline
\end{tabular}


A plot of $\log \mathrm{k}_{\mathrm{obs}} v s . \log [\mathrm{PIA}]$ is a straight line and passes through the origin. The effect of varying the solvent composition was studied by following the rate of the reaction by increasing the $\%$ of $t$-butyl alcohol. Rate of oxidation increases with decrease in dielectric constant of the medium. The addition of sodium perchlorate has no significant effect on the reaction rate showing the absence of primary salt effect.

\section{Mechanism and rate law}

$\mathrm{PhI}(\mathrm{OAc})_{2}$ is the active oxidizing species at low concentration of acid $\left[\mathrm{H}^{+}\right] 2.5 \times 10^{-3} \mathrm{M}$

$$
\begin{aligned}
& \mathrm{BzOH}+\mathrm{PIA} \stackrel{\mathrm{K}}{\rightleftharpoons} \text { Complex } \\
& \text { Complex }+\mathrm{H}^{+} \stackrel{\mathrm{k}_{1}}{\stackrel{\text { slow and rate }}{\text { determinig }}} \text { Products }
\end{aligned}
$$

The rate law derived is as follows:

$$
\begin{aligned}
& \text { Rate }=-\mathrm{d}[\mathrm{PIA}] / \mathrm{dt}=\mathrm{k}_{1}[\text { Complex }]\left[\mathrm{H}^{+}\right], \\
& \text {Complex }=[\mathrm{BzOH}][\mathrm{PIA}] \\
& -\mathrm{d}[\mathrm{PIA}] / \mathrm{dt}=[\mathrm{BzOH}][\mathrm{PIA}]\left[\mathrm{H}^{+}\right]
\end{aligned}
$$

\section{Correlation analysis of reactivity}

Eight meta- and para-substituted benzyl alcohols have been subjected to oxidation by PIA at four different temperatures in similar conditions for the parent compound. The rate constants along with the activation parameters for the reaction of substituted benzyl alcohols with PIA are given in Table 2 .

Table 2 Rate constants and activation parameters for the oxidation of meta- and parasubstituted benzyl alcohols by PIA $\mathrm{k}_{\mathrm{obs}} \times 10^{3}\left(\mathrm{~s}^{-1}\right)$

\begin{tabular}{llllllll}
\hline Substituents & $293 \mathrm{~K}$ & $303 \mathrm{~K}$ & $313 \mathrm{~K}$ & $323 \mathrm{~K}$ & $\Delta \mathrm{H}^{\#}$ & $\Delta \mathrm{S}^{\#}$ & $\mathrm{R}$ \\
\hline$p-\mathrm{H}$ & 90.00 & 181.33 & 378.67 & 786.67 & 54.38 & -79.55 & 0.999 \\
$p-\mathrm{OCH}_{3}$ & 338.05 & 486.40 & 699.84 & 1006.94 & 26.06 & -165.3 & 0.999 \\
$p-\mathrm{CH}_{3}$ & 191.00 & 319.88 & 533.33 & 889.40 & 37.77 & -129.8 & 0.999 \\
$p-\mathrm{F}$ & 44.2 & 86.69 & 153.46 & 271.65 & 44.84 & -117.6 & 0.999 \\
$p-\mathrm{Cl}$ & 42.0 & 81.47 & 150.31 & 277.32 & 46.83 & -111.4 & 0.999 \\
$p-\mathrm{Br}$ & 43.00 & 89.33 & 156.68 & 274.80 & 45.72 & -114.7 & 0.999 \\
$p-\mathrm{I}$ & 37.00 & 76.73 & 153.46 & 306.92 & 52.84 & -92.03 & 0.999 \\
$p-\mathrm{NO}_{2}$ & 8.50 & 19.31 & 44.67 & 103.29 & 62.97 & -69.86 & 0.999 \\
$p-\mathrm{COOH}$ & 20.00 & 43.70 & 87.28 & 174.32 & 54.03 & -92.98 & 0.996 \\
$m-\mathrm{OCH}$ & 180.00 & 293.09 & 413.99 & 584.76 & 28.03 & -163.2 & 0.998 \\
$m-\mathrm{CH}$ & 227.00 & 346.73 & 500.03 & 721.10 & 27.68 & -162.8 & 0.999 \\
$m-\mathrm{F}$ & 45.00 & 73.28 & 146.55 & 293.00 & 47.00 & -110.9 & 0.999 \\
$m-\mathrm{Cl}$ & 30.00 & 61.80 & 111.43 & 200.90 & 47.03 & -113.3 & 0.999 \\
$m-\mathrm{Br}$ & 32.00 & 58.61 & 125.31 & 267.92 & 53.49 & -91.50 & 0.996 \\
$m-\mathrm{I}$ & 29.00 & 60.67 & 114.55 & 216.28 & 49.91 & -103.8 & 0.999 \\
$m-\mathrm{NO}_{2}$ & 14.00 & 31.47 & 76.73 & 132.72 & 57.67 & -83.41 & 0.997 \\
$m-\mathrm{COOH}$ & 15.10 & 37.22 & 92.00 & 228.75 & 68.62 & -45.78 & 0.999 \\
\hline
\end{tabular}

A linear isokinetic relationship ${ }^{13}$ has been observed by plotting $\Delta H^{\#}$ versus $\Delta S^{\#}$

Thus a common mechanism may be responsible for oxidation of all the substituted benzyl alcholos ${ }^{14}$ under investigation. The rate data of meta- and para-substituted benzyl alcohols were subjected to multiple regression analysis in terms of $\mathrm{Taft}^{15}$ and Swains ${ }^{16}$ dual 
substituent parameter (DSP) equation. The results of this correlation are given in Table 3. The statistical parameters, standard deviation (SD), coefficient of multiple correlations (R) and the parameters for precision ${ }^{17,18}$ ( $\mathrm{f}$ and $\psi$ ) are also presented in Table 3.

Table 3 Results of multiple regression analysis of the rate data of meta- and para- substituted Benzyl alcohols by PIA at $303 \mathrm{~K}$

\begin{tabular}{llllllll}
\hline Substituent constants & $\Lambda$ & $\rho_{\mathrm{I}}$ & $\rho_{\mathrm{R}}$ & $\mathrm{R}$ & $\mathrm{SD}$ & $\mathrm{F}$ & $\Psi$ \\
\hline Meta-compounds $\sigma_{\mathrm{I}} \sigma_{\mathrm{R}}{ }^{0}$ & -0.7179 & -1.3630 & -0.9053 & 0.9174 & 0.1471 & 0.1173 & 0.1311 \\
$\sigma_{\mathrm{I}} \sigma_{\mathrm{R}}{ }^{(\mathrm{BA})}$ & -0.7163 & -1.3713 & -0.7608 & 0.9455 & 0.1438 & 0.3256 & 0.3759 \\
$\sigma_{\mathrm{I}} \sigma_{\mathrm{R}}{ }^{-}$ & -0.6765 & -1.2577 & -0.5302 & 0.9108 & 0.1822 & 0.4127 & 0.4766 \\
$\sigma_{\mathrm{I}} \sigma_{\mathrm{R}}{ }^{+}$ & -0.7525 & -1.3407 & -0.5380 & 0.9545 & 0.1316 & 0.2980 & 0.3441 \\
$\mathrm{~F}, \mathrm{R}$ & -0.6599 & -0.7504 & -0.2462 & 0.9625 & 0.1216 & 0.2712 & 0.3209 \\
Para-compounds $\sigma_{\mathrm{I}} \sigma_{\mathrm{R}}{ }^{0}$ & -0.7174 & -1.3875 & -1.3775 & 0.9783 & 0.1022 & 0.2072 & 0.2392 \\
$\sigma_{\mathrm{I}} \sigma_{\mathrm{R}}{ }^{(\mathrm{BA})}$ & -0.7090 & -1.3989 & -1.1174 & 0.9803 & 0.0973 & 0.1973 & 0.2258 \\
$\sigma_{\mathrm{I}} \sigma_{\mathrm{R}}{ }^{-}$ & -0.6581 & -1.2229. & -0.8328 & 0.9465 & 0.1592 & 0.3227 & 0.3727 \\
$\sigma_{\mathrm{I}} \sigma_{\mathrm{R}}{ }^{+}$ & -0.7611 & -1.3542 & -0.7862 & 0.9929 & 0.0585 & 0.1185 & 0.1368 \\
$\mathrm{~F}, \mathrm{R}$ & -0.7066 & -0.6497 & -0.4068 & 0.9896 & 0.0734 & 0.1436 & 0.1696 \\
\hline
\end{tabular}

The multiple regression analysis was carried out with dual substituent constants $\sigma_{\mathrm{I}} \sigma_{\mathrm{R}}{ }^{\circ}$, $\sigma_{\mathrm{I}} \sigma_{\mathrm{R}}{ }^{(\mathrm{BA})}, \sigma_{\mathrm{I}} \sigma_{\mathrm{R}}{ }^{-}, \sigma_{\mathrm{I}} \sigma_{\mathrm{R}}{ }^{+}$and $\mathrm{F}, \mathrm{R}$. The rate of oxidation of meta-compounds showed good correlation with $(\mathrm{F}, \mathrm{R})$ values. para-compounds showed comparatively good correlation with $\sigma_{\mathrm{I}} \sigma_{\mathrm{R}}{ }^{+}$. The values of statistical data for goodness of fit $\psi$ and $\mathrm{f}$ are also point the same conclusion. The coefficients for reaction constants $\rho_{\mathrm{I}}, \rho_{\mathrm{R}}$ at four different temperatures and the statistical parameters $\mathrm{R}, \mathrm{SE}, \mathrm{f}$ and $\psi$ are given in Table 4.The value of $\lambda\left(\lambda=\rho_{\mathrm{I}} / \rho_{\mathrm{R}}\right)$ for the para-compounds are around 0.60 and for meta-compounds it is around 0.40 indicating para-compounds are more susceptible to resonance effects than to field effect and metacompounds are more susceptible to field effects than to resonance effects. The percentage contributions of resonance effect to the total polar effects for para-compounds have been calculated using the following equation,

$$
\mathrm{P}_{\mathrm{R}}=\left(\rho_{\mathrm{R}}\right) \times 100 /\left(\rho_{\mathrm{I})+}\left(\rho_{\mathrm{R}}\right)\right.
$$

The regression coefficients of $\sigma_{I}$ and $\sigma_{R}$ are negative indicating that electron releasing groups accelerate the reaction. The contribution of resonance parameters to the total effect have also been determined at four temperatures. For para-compounds the resonance contribution is around 38 per cent of the total polar effect. whereas, for meta-compounds it is around 25 per cent These values are given in Table 4 .

Table 4. Temperature dependence of the reaction constants for the oxidation of meta- and para-substituted benzyl alcohols by PIA

\begin{tabular}{lllllllll}
\hline $\mathrm{T}, \mathrm{K}$ & $\rho_{\mathrm{I}}$ & $\rho_{\mathrm{R}}$ & $\lambda$ & $\mathrm{R}$ & $\mathrm{SE}$ & $\mathrm{F}$ & $\Psi$ & $\mathrm{PR}$ \\
\hline Meta-compounds at 293 & -0.787 & -0.304 & 0.386 & 0.9647 & 0.1262 & 0.1025 & 0.1184 & 27.87 \\
303 & -0750 & -0.246 & 0.328 & 0.9625 & 0.1216 & 0.2712 & 0.3209 & 24.70 \\
313 & -0.663 & -0.169 & 0.256 & 0.957 & 0.1059 & 0.2869 & 0.3454 & 20.38 \\
323 & -0.643 & -0.132 & 0.207 & 0.9695 & 0.0824 & 0.2447 & 0.2896 & 17.11 \\
Para-compounds at 293 & -1.479 & -0.923 & 0.624 & 0.9924 & 0.0667 & 0.0504 & 0.0572 & 38.43 \\
303 & -1.354 & -0.786 & 0.580 & 0.9929 & 0.0585 & 0.1185 & 0.1368 & 36.73 \\
313 & -1.279 & -0.641 & 0.501 & 0.9901 & 0.0624 & 0.1373 & 0.1628 & 33.39 \\
323 & -1.203 & -0.497 & 0.413 & 0.9900 & 0.0616 & 0.1532 & 0.1813 & 29.25 \\
\hline
\end{tabular}




\section{Conclusion}

Oxidation of benzyl alcohol and some meta- and para- substituted alcohols by phenyliodoso acetate (PIA) in $t$-butyl alcohol-water medium (50:50) leads to the formation of corresponding benzaldehyde. The reaction proceeds through a complex formation type. PIA acts as a good oxidizing agent and can be used in organic synthesis. Field effect influences the rate of the reaction both in meta- and para-substituted compounds when compare to resonance effect.

\section{References}

1. Pausaucker K M, J Chem Soc., 1953, 1,107.

2. Krishnamurthi T K and Venkatasubramanian N, Indian J Chem., 1973, 11, 1946.

3. Rangarajan K and Mathai I M, Indian J Chem., 1978, 16B, 1097.

4. Radhakrishnamurthi P S and Panda H P, Gazz Clim Ital, 1979, 109, 637.

5. Subas C Pati and Dev B R, Z Phys Chem., 1981, 262(1), 176.

6. Uma M and Kalavathi C S, Curr Sci., 1982, 51(8), 412.

7. Bhavani N and Lilly K, Oxid Commun., 1997, 20(1), 87.

8. Karunakaran K, Gurumurthy R and Sathiya Narayanan K, Oxid Commun., 1993, 16(3-4), 351.

9. Karunakaran K, Nagarajan S, Kanagavel D, Jegadish T N, Palanisamy P N and Elango K P, Oxid Commun., 1997, 20(4), 576-578.

10. Boeskan J and Schneider G C C C, J Prakt Chem., 1931, 131, 285.

11. George A Kraus and Iykon Kim, Tetrahedron, 2003, 59, 7935-7937.

12. Wei Zhong and Daniel Little.R, Tetrahedron, 2009, 65, 10784-10790.

13. Exner.O, Collect Czech Chem Commun., 1964, 29, 1094.

14. Srinivasan C, Chellamani S and Rajagopal.A, J Org Chem., 1985, 50, 1201.

15. Dayal S K, Ehrenson S and Taft R W, J Am Chem Soc., 1974, 94, 113.

16. Swain C S, Unger S H, Rosenquist N R and Swain M S, J Am Chem Soc., 1985, 105, 492.

17. Ehrenson.S, Brownlee R T C and Taft R W, Progr Phy Org Chem., 1973, 10, 1.

18. Exner O, Collect Czech Chem Commun., 1966, 31, 3222-3251 


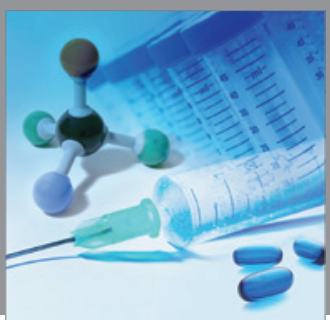

International Journal of

Medicinal Chemistry

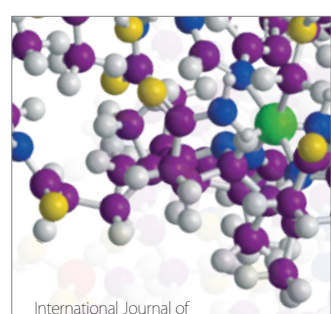

Carbohydrate Chemistry

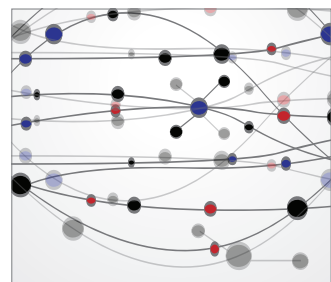

The Scientific World Journal
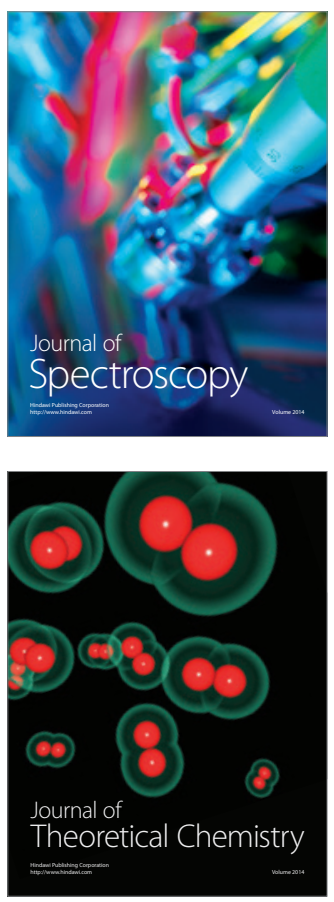
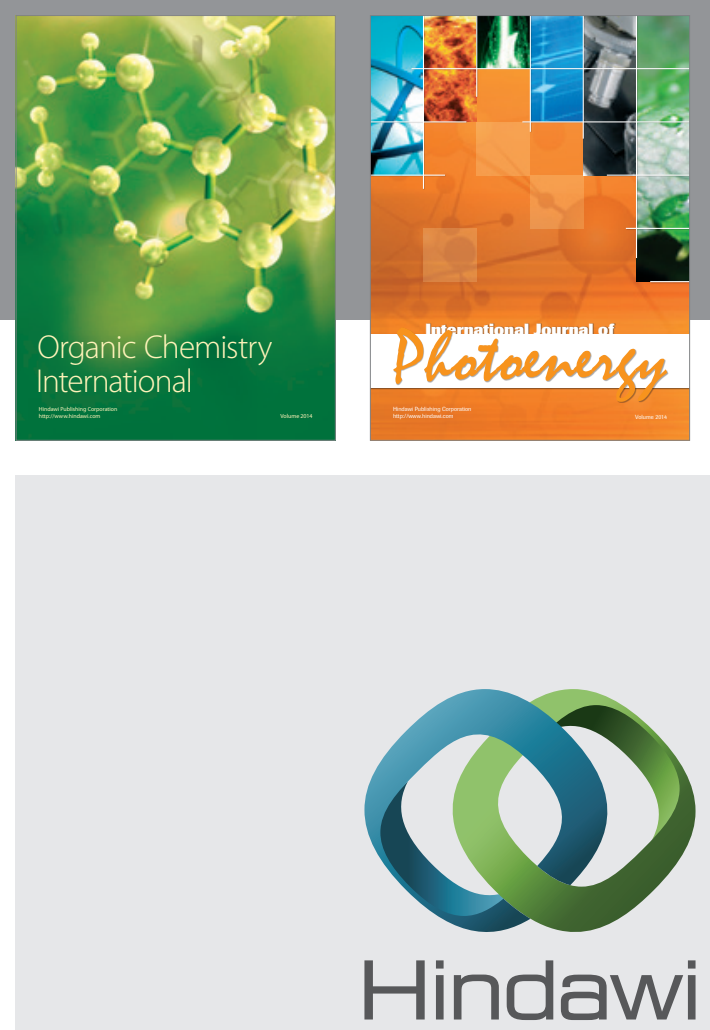

Submit your manuscripts at

http://www.hindawi.com
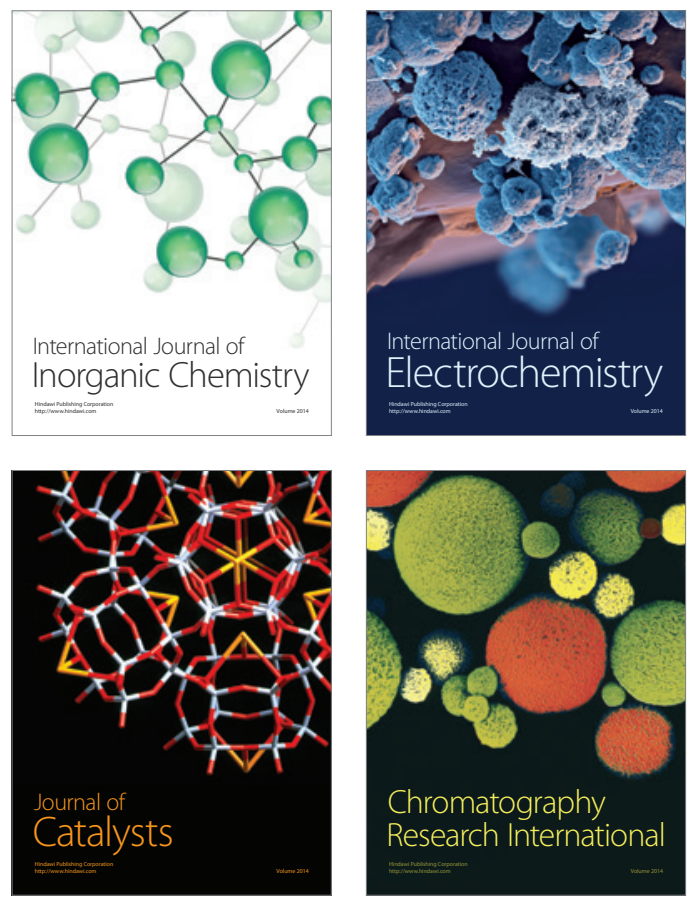
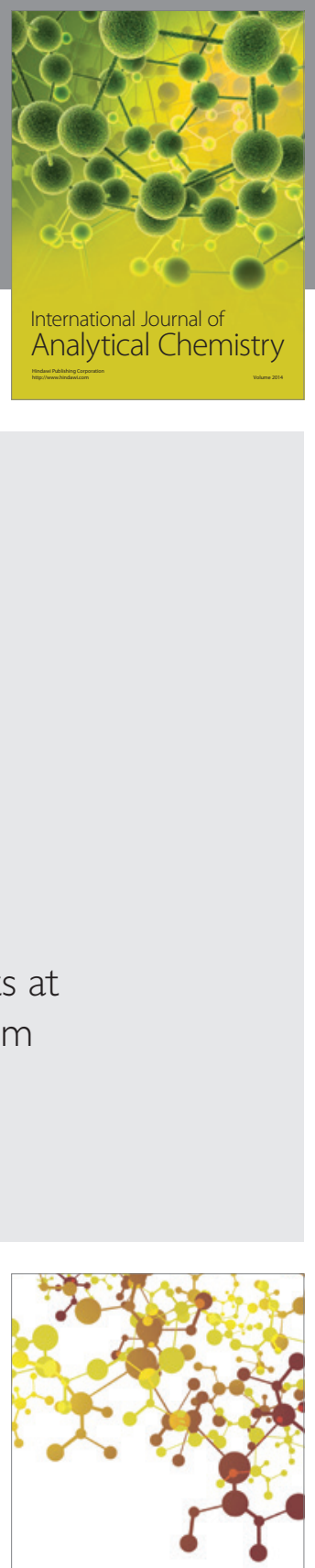

Journal of

Applied Chemistry
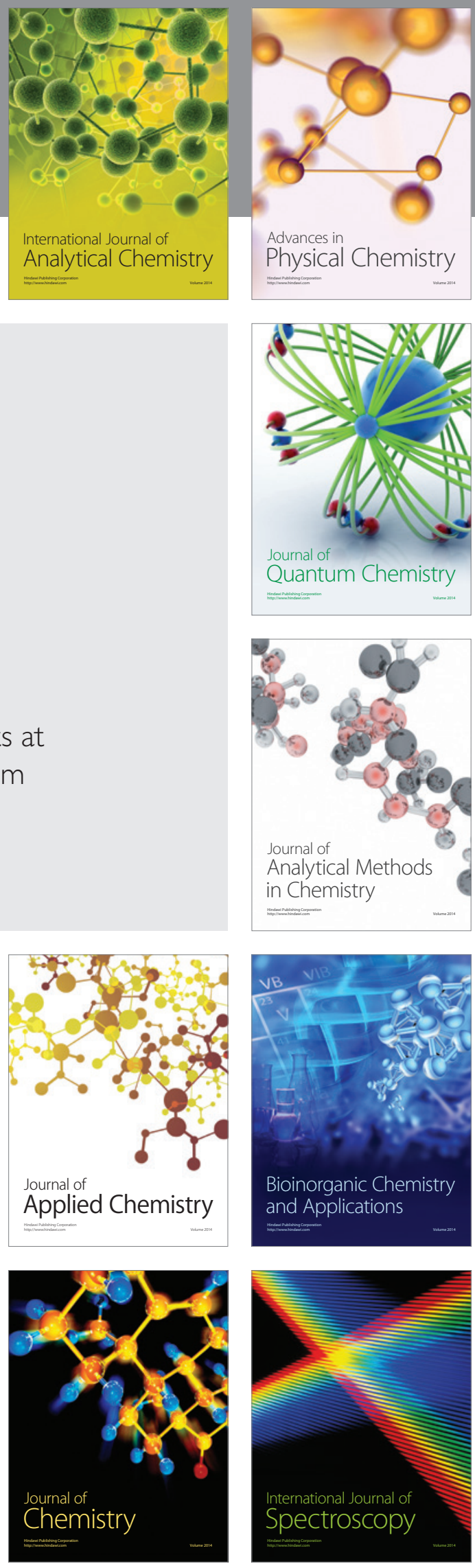